\title{
Nest of Origin Predicts Adult Neuron Addition Rates in the Vocal Control System of the Zebra Finch
}

\author{
Patrick Hurley Carolyn Pytte John R. Kirn \\ Biology Department, Neuroscience \& Behavior Program, Hall-Atwater \& Shanklin Labs, Wesleyan University, \\ Middletown, Conn., USA
}

\section{Key Words}

Adult neurogenesis $\cdot$ Birdsong $\cdot$ Heritability $\cdot$ Song system on neurogenesis and the capacity to adjust rates of neuron addition in response to adult auditory experience is established early in development. Copyright $\odot 2008$ s. Karger AG, Basel

\begin{abstract}
Neurogenesis and neuronal replacement in adulthood represent dramatic forms of plasticity that might serve as a substrate for behavioral flexibility. In songbirds, neurons are continually replaced in HVC (used as a proper name), a premotor region necessary for the production of learned vocalizations. There are large individual differences in HVC neuron addition. Some of this variation is probably due to individual differences in adult experience; however, it is also possible that heritability or experience early in development constrains the levels of adult neuron addition. As a step toward addressing the latter two possibilities, we explored the extent to which nest of origin predicts rates of HVC neuron addition in adult male zebra finches. One month after injections of $\left[{ }^{3} \mathrm{H}\right]$-thymidine to mark dividing cells, neuron addition in HVC was found to co-vary among birds that had been nest mates, even when they were housed in different cages as adults. We also tested whether nest mate co-variation might be due to shared adult auditory experience by measuring neuron addition in nest mate pairs after one member was deafened. There were significant differences in neuron addition between hearing and deaf birds but nest mate relationships persisted. These results suggest that variation in genotype and/or early pre- or postnatal experience can account for a large fraction of adult variation in rates of neuron addition. These results also suggest that a major constraint
\end{abstract}

\section{Introduction}

Naturally occurring neuron replacement is the most extreme form of adult neural plasticity. Although the specific functions of adult neurogenesis in mammals and birds are unclear, evidence has accumulated suggesting a link between the proliferation or survival of new neurons and perceptual or motor learning [Nottebohm et al., 1990; Wilbrecht and Kirn, 2004; Leuner et al., 2006]. For example, new neuron incorporation is augmented when mammals and birds are exposed to enriched environments [Lipkind et al., 2002; Leuner et al., 2006; Wilbrecht et al., 2006]. In the adult zebra finch, transfer from an impoverished social environment to a large aviary with many birds augments rates of neuron addition in the vocal control region HVC (used as a proper name) [Lipkind et al., 2002]. Social isolation during development, which delays the end of the critical period for song acquisition [Eales, 1985; Morrison and Nottebohm, 1993], also delays the normal decline in HVC neuron addition in zebra finches [Wilbrecht et al., 2006]. In the broadest sense, neuronal addition and replacement might be considered processes that enable adult animals to adjust adaptively to environmental variability.

\section{KARGER}

(ㄷ) 2008 S. Karger AG, Basel

Fax +41613061234

E-Mail karger@karger.ch

www.karger.com
Accessible online at: www.karger.com/bbe
John Kirn

Wesleyan University, Biology Department

237 Church St.

Middletown, CT 06459 (USA)

Tel. +1 860345 8286, Fax +1 860685 2439, E-Mail jrkirn@wesleyan.edu 
HVC is necessary for learned song production and might play a role in song perception as well [Nottebohm et al., 1976; Brenowitz, 1991; Gentner et al., 2000]. One way in which social enrichment might influence HVC neuron addition is by promoting singing. Natural variation in singing rates correlates positively with HVC neuron addition and suppressing singing decreases the addition of new HVC neurons in adult canaries [Li et al., 2000; Alvarez-Borda and Nottebohm, 2002]. Song-related auditory, motor or sensory-motor activity could, therefore, represent experiential factors that regulate adult HVC neuron addition. The potential role of song-related motor activity has not been explored; however, adult-formed HVC neurons respond to sound [Paton and Nottebohm, 1984] and deafening in adulthood reduces the number of neurons added to HVC [Wang et al., 1999]. This suggests that auditory experience, perhaps associated with singing, plays an important role in regulating neuron addition.

Growing evidence, however, suggests that variation in other neural attributes in the vocal control system is heritable [DeVoogd, 2004]. There are large individual differences in HVC neuron addition in adult songbirds. Although some of this variability is probably due to variation in adult experience, at least some of the variation could be heritable or due to more long-term effects of experiential factors acting early in life. Common to both of these latter scenarios is the notion that rules governing adult neurogenesis are established early in development. As a step toward addressing this possibility, we tested whether male zebra finches that had been nest mates covaried in rates of adult HVC neuron addition. We found that a significant amount of the variability in HVC neuron incorporation could be accounted for by a bird's nest of origin. We then explored the extent to which co-variation among nest mates could be accounted for by shared adult auditory experience by deafening one member of several nest mate pairs. Deafened birds had significantly higher rates of HVC neuron addition when compared to hearing birds that had been their nest mates. However, nest mate co-variation persisted. These results suggest that rates of HVC neuron incorporation are regulated, in part, by adult experience but that heritability or early experience also plays a role.

\section{Materials and Methods}

\section{Subjects}

All animal experimentation conformed to NIH guidelines and was approved in advance by the Institutional Animal Care and Use Committee at Wesleyan University. All birds used were males obtained from our breeding colony $(n=46$ birds from 20 nests). Subjects came from one of two breeding conditions. Many males were hatched in a large aviary where they could interact with their parents and other birds of both sexes $(n=25 ; 10$ nest mate groups). Remaining males ( $\mathrm{n}=21 ; 10$ nest mate groups) were hatched in smaller cages where interactions were limited to biological parents and siblings. At 70-90 days of age, all subjects were housed in single sex groups of 4-8 per cage and at the beginning of the study, all birds were placed in groups of 4 per cage. In all but one case, there were males from at least 2 nests in each cage. Birds were housed on a $14: 10 \mathrm{~h}$ light/dark cycle at $22^{\circ} \mathrm{C}$. Seed and water were available ad libitum, supplemented with a mixture of cooked eggs and baby cereal every $2-3$ days. All birds used in this study were between 4 and 11 months of age at the time of $\left[{ }^{3} \mathrm{H}\right]$-thymidine injections. Although HVC size and total neuron number do not change over this age range, HVC neuron incorporation decreases [Wang et al., 2002]. In the present work, procedures were employed to measure contributions of nest of origin to adult neuron addition, independent of age at sacrifice (see 'Statistics').

\section{$\left[{ }^{3} \mathrm{H}\right]$-Thymidine Injections}

Cell birth dating followed the same protocols as in Wang et al. $[1999,2002]$. All birds received intramuscular (pectoral muscles) injections of $\left[{ }^{3} \mathrm{H}\right]$-thymidine (methy- $\left[{ }^{3} \mathrm{H}\right]$ thymidine, $2.5 \mu \mathrm{Ci} / \mathrm{g}$; 6.7 Ci/mmol; $1 \mathrm{Ci}=37 \mathrm{GBq}$; New England Nuclear Corp., New Life Products, Boston, Mass., USA) every 12 h (8 a.m. and 8 p.m.) for 4 consecutive days to label dividing cells. Birds were killed 24 days after the last $\left[{ }^{3} \mathrm{H}\right]$-thymidine injection.

\section{Deafening Surgery}

In 13 nest mate pairs, one individual was deafened by bilateral cochlea removal 2-3 weeks before $\left[{ }^{3} \mathrm{H}\right]$-thymidine treatment as described elsewhere [Wang et al., 1999]. Birds were anesthetized with intramuscular injections of equal amounts of ketamine (Ketalar, Parke-Davis, Fort Dodge, IA; 0.028-0.035 ml/bird, 10 $\mathrm{mg} / \mathrm{ml}$ ) and xylazine (Rompun, Haver, The Butler Co., Columbus, Ohio, USA; $0.028-0.035 \mathrm{ml} / \mathrm{bird}, 20 \mathrm{mg} / \mathrm{ml}$ ). Feathers were removed behind the ears, and an incision was made in the skin just caudal to the ear canal. The muscles were separated and the bone was opened just over the semicircular canal that encases the cochlea. A small rigid wire hook was used to remove the cochlea. Tissue adhesive was applied to the opening in the temporal bone to minimize drainage of the semicircular canal. The incision through the skin was sealed with cyanoacrylate and sutures. All deafened birds were allowed to recover for $24-30 \mathrm{~h}$ and then returned to their original cage and cage mates. All deaf birds could perch and fly $30 \mathrm{~h}$ after the procedure.

\section{Perfusions and Tissue Processing}

All birds were deeply anesthetized by inhalation of methoxyflurane (Metofane; Mallinckrodt Inc., Mundelgn, Ill., USA), then perfused through the left ventricle with $20-30 \mathrm{ml}$ of $0.1 \mathrm{M}$ PBS ( $\mathrm{pH} 7.4$ ) followed by $40-50 \mathrm{ml}$ of $4 \%$ paraformaldehyde (in $0.1 \mathrm{M}$ PBS; pH 7.4). The brains were post-fixed overnight in the same fixative, washed in PBS, dehydrated in increasing concentrations of ethanol and embedded in polyethylene glycol (PEG, Polysciences Inc., Warrington, Pa., USA) [Smithson et al., 1983; Clayton and Alvarez-Buylla, 1989]. Sagittal brain sections containing $\mathrm{HVC}$ were cut at $6 \mu \mathrm{m}$ on a rotary microtome and every 8 th sec- 


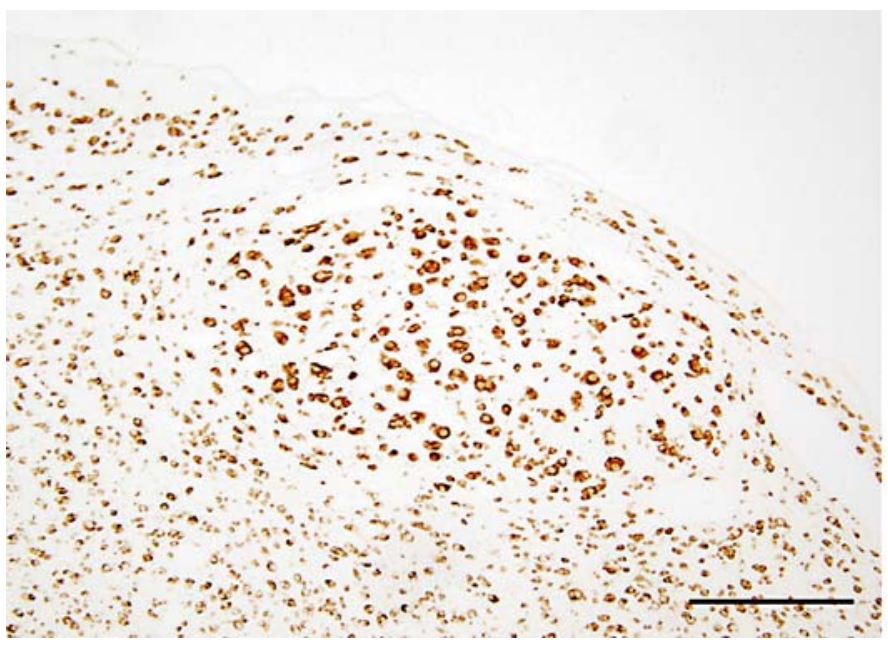

Fig. 1. Photomicrographs of HVC (left) and an adult-formed HVC neuron (right) in $6-\mu \mathrm{m}$ sagittal sections. Tissue was processed for visualization of adult-formed neurons using $\left[{ }^{3} \mathrm{H}\right]$-thymidine autoradiography combined with immunohistochemistry using antibodies against the neuron specific protein $\mathrm{Hu}$. HVC (left) can be distinguished from surrounding tissue by having larger, more in-

tion was mounted onto Superfrost slides and air-dried. Slides were then stored at $-20^{\circ} \mathrm{C}$ until processed for immunohistochemistry.

\section{Autoradiography}

Sections were processed for the autoradiographic detection of $\left[{ }^{3} \mathrm{H}\right]$-labeled (i.e., adult-formed) cells. Following immunohistochemistry (see below), tissue was delipidized in increasing concentrations of ethanol, cleared in xylene, rehydrated and stored in a dust-free oven overnight. In a darkroom under a sodium safelight, slides were dipped in nuclear track emulsion (NTB; Eastman Kodak Company, Rochester, N.Y., USA) in a $37-39^{\circ} \mathrm{C}$ water bath, allowed to dry at $37^{\circ} \mathrm{C}$ in a light-tight oven for $4 \mathrm{~h}$ and then stored with desiccant (Drierite) for 28 days at $4^{\circ} \mathrm{C}$ in the dark. Slides were then developed (Kodak D-19 developer) at $17^{\circ} \mathrm{C}$ for $3 \mathrm{~min}$, rinsed in tap water at $19^{\circ} \mathrm{C}$ for $1 \mathrm{~min}$, and fixed (Kodak standard fixer) at $19^{\circ} \mathrm{C}$ for $12 \mathrm{~min}$ followed by running tap water for $10 \mathrm{~min}$. Sections were then dehydrated with a graded ethanol series, cleared in xylene, and coverslipped with Krystalon (Harleco, EM Science, Gibbstown, N.Y., USA).

\section{Immunohistochemistry}

To distinguish neurons from non-neuronal cells, we used the neuron specific anti-Hu antibody [Barami et al., 1995]. Following protocols described previously [Wang et al., 2002] sections were brought to room temperature and then washed three times in $0.1 \mathrm{M}$ phosphate buffer (PB). Endogenous peroxidase activity was reduced with a 20 -min methanol/hydrogen peroxide rinse and then sections were exposed to a blocking solution of $10 \%$ Normal Goat Serum and $0.3 \%$ Triton X for $1 \mathrm{~h}$. They were then treated with the same blocking solution plus mouse anti-Hu Mab 16A11 primary antibody (1:10, Molecular Probes, Eugene, Oreg., USA)

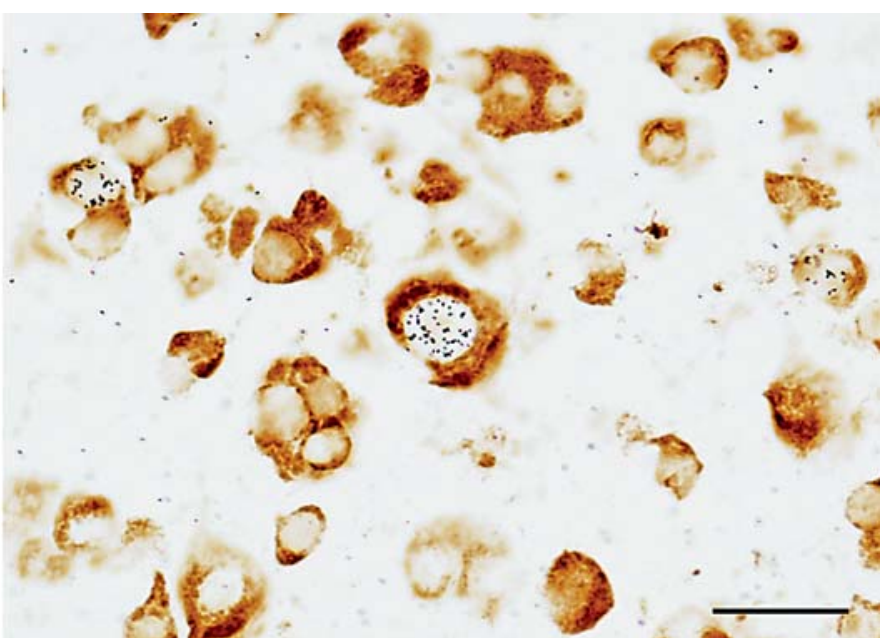

tensely immunoreactive neurons. An example of an adult-formed HVC neuron (right), identified by cytoplasmic anti-Hu staining and autoradiographically exposed silver grains (black dots) overlying the cell nucleus. In the left panel, dorsal is up and rostral is to the right. Scale bar: $200 \mu \mathrm{m}$ in left panel and $10 \mu \mathrm{m}$ in right panel.

at $4^{\circ} \mathrm{C}$ overnight. Sections were exposed at room temperature to biotinylated goat anti-mouse $\operatorname{IgG}$ (1:200, Vector Laboratories, Burlingame, Calif., USA) in blocking solution. Sections were then processed using the ABC Elite Kit (Vector Laboratories) followed by a 10 -min wash in $0.1 \mathrm{M} \mathrm{PB}$. This was followed by exposure to diaminobenzidine (DAB, Sigma, Inc., Calif., USA) for 8-10 min. Sections were rinsed several times in de-ionized water, allowed to air dry and stored in a dust free environment until autoradiographic processing.

\section{Data Collection and Analyses}

Slides were coded so that all data were collected blind. Area measurements and cell counting were carried out using $10 \times$ air and $60 \times$ oil objectives and brightfield optics on a computeryoked microscope system (Olympus BX50; Neurolucida, MicroBrightField Inc., Colchester, Vt., USA). The HVC was clearly delimited by $\mathrm{Hu}$ staining at $10 \times$ magnification and the boundaries were drawn for area measurements. Cells were classified as neurons if the nucleus was surrounded by Hu labeling [Barami et al., 1995] and as adult-formed neurons if labeled by $\mathrm{Hu}$ and the density of exposed silver grains overlying the nucleus was at least 20 times higher than background (fig. 1). In 12-15 equally spaced sections, HVC was completely analyzed in one hemisphere from each bird. The number of double labeled cells (HU+ $\left[{ }^{3} \mathrm{H}\right]$-thymidine) was summed across sections and divided by the volume sampled (area $\times$ section thickness) to generate estimates of labeled cell densities $/ \mathrm{mm}^{3}$. HVC volume was reconstructed by summing the cross-sectional areas of analyzed sections, multiplying by sampling interval and section thickness. The total number of new neurons was estimated by multiplying cell densities by HVC volume. All $\left[{ }^{3} \mathrm{H}\right]$-thymidine labeled neuronal nuclear diameters were measured and the Konigsmark correction for cell split- 


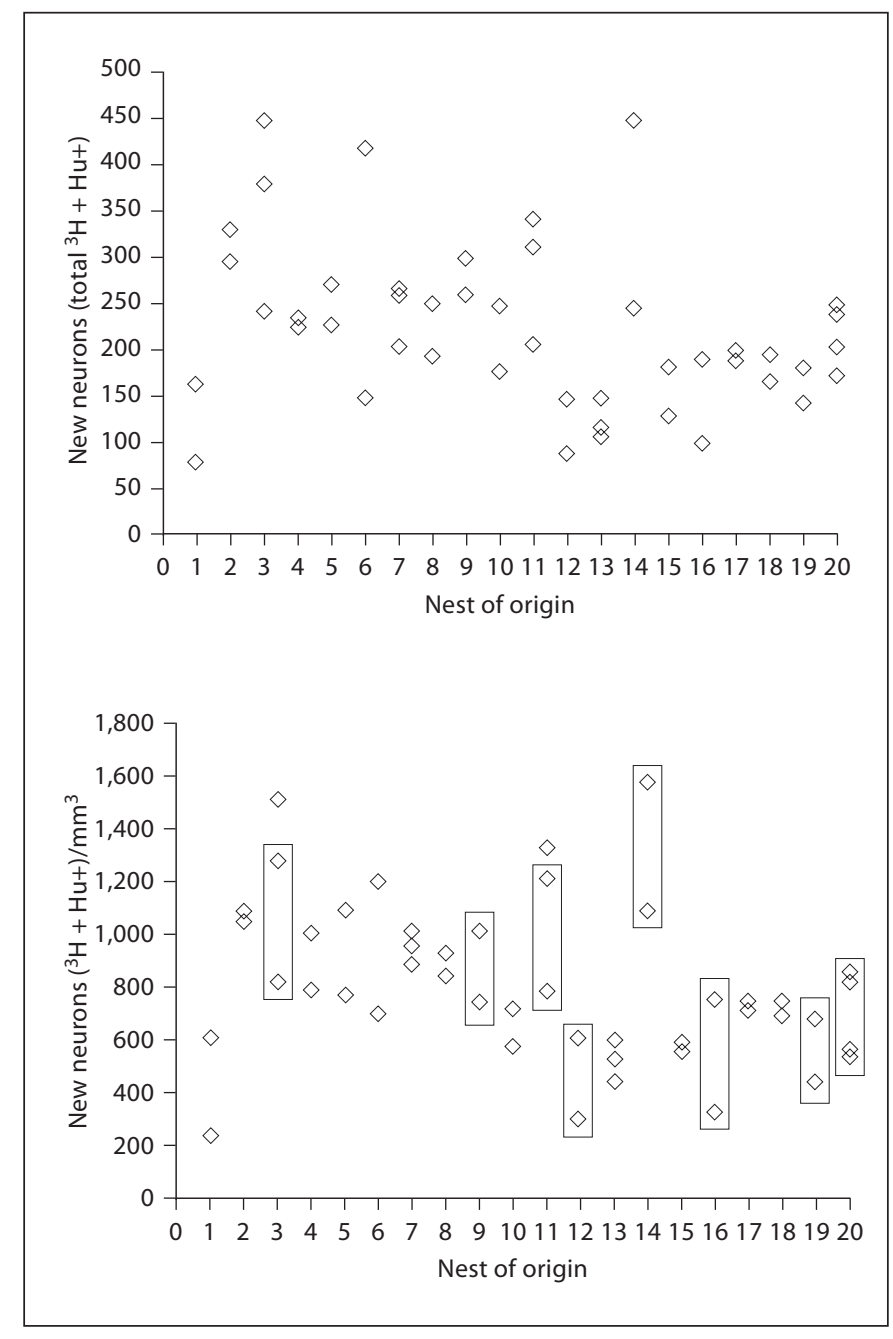

Fig. 2. Estimates of the total number (upper panel) and density (lower panel) of new HVC neurons ([$\left.{ }^{3} \mathrm{H}\right]$-thymidine+ $\left.\mathrm{Hu}+\right) 24$ days after the last of 4 days of treatment with the cell birth dater $\left[{ }^{3} \mathrm{H}\right]$-thymidine in adult male zebra finches that were nest mates. Each diamond represents an individual bird. Nest mate groups are arranged on the $\mathrm{x}$-axis according to age at sacrifice $(1=145 \mathrm{~d}$, $20=315 \mathrm{~d})$. Nest mates that were housed in the same cage as adults are demarcated with rectangles in the lower panel. Nest mates covaried significantly in the total number and density of new neurons and this was true even when analyses were restricted to families where nest mates were not all housed together (see text for details).

ting [Konigsmark, 1970; Coggeshall and Lekan, 1996] was used in calculating cell densities and total cell numbers.

\section{Statistics}

Analyses of the Relationship between Family Membership and Neuronal Attributes. One-way analysis of variance (ANOVA) was used to perform intra-class correlation analyses of nest mate groups [Zar, 1984]. Two-way ANOVAs were performed to explore the independent variables of nest of origin and housing condition.

Analyses Employed to Minimize Potentially Confounding Effects of Age at Sacrifice. As mentioned previously, neuron addition to HVC decreases with adult age [Wang et al., 2002]. In the present work, age at sacrifice was a potential confound because it often co-varied with nest of origin. Preliminary analyses revealed that age could explain a small but statistically significant amount of the between-nest variability. Because there was essentially no within-nest variability in age at sacrifice, this precluded the use of analysis of covariance to examine contributions of nest of origin, independently of age. To circumvent this problem, we performed residuals analyses. Each dependent variable was first regressed on age, and then residual variation from the best fitting linear regression line was used in ANOVA tests on nest of origin [Sokal and Rohlf, 1981]. In other words, ANOVA tests were used to explore the extent to which nest of origin could explain variation unaccounted for by age at sacrifice. As recommended by Darlington and Smulders [2001], we subtracted one degree of freedom when calculating the mean square error term and the $F$ values in cases where age was a significant confound. This conservative measure increased numerical $p$ values slightly but essentially the same statistical conclusions were obtained with and without this modification.

Analyses of Hearing and Deaf Nest Mate Pairs. Matched samples $t$ tests were used to compare hearing birds and their deaf nest mates. All statistical analyses were performed using JMP software (JMP, SAS Institute, Cary, N.C., USA).

\section{Results}

There was a significant relationship between nest of origin and the number of adult-formed neurons subsequently added to $\mathrm{HVC}$ at $4-11$ months of age (fig. 2, upper panel; $\operatorname{ANOVA}, \mathrm{F}_{(19,25)}=2.63, \mathrm{p}=0.012$; adjusted $\mathrm{R}^{2}=$ 0.41. HVC volume may be heritable [Airey et al., 2000] and in the present work, HVC size was used to calculate estimates of total new neuron number; however, new neuron density (new neurons $/ \mathrm{mm}^{3}$ ), a measure that is less sensitive to HVC size, also co-varied significantly with nest of origin (fig. 2, lower panel; $\mathrm{F}_{(19,25)}=2.819, \mathrm{p}=0.008$; adjusted $\mathrm{R}^{2}=0.45$ ).

When we restricted our analysis to offspring of individually housed breeding pairs (and, therefore, birds of known parentage) we obtained similar findings (estimates of total new neuron number $\left(\mathrm{F}_{(9,11)}=3.23, \mathrm{p}=\right.$ 0.035 , adjusted $\mathrm{R}^{2}=0.50$; estimates of new neuron densities: $\mathrm{F}_{(9,11)}=3.71, \mathrm{p}=0.022$, adjusted $\mathrm{R}^{2}=0.55$; data not shown). There was no significant relationship between nest of origin and HVC volume $\left(\mathrm{F}_{(9,11)}=0.53, \mathrm{p}=0.83\right)$ or estimates of total neuron number $\left(\mathrm{F}_{(9,11)}=1.17, \mathrm{p}=\right.$ 0.39 ). 

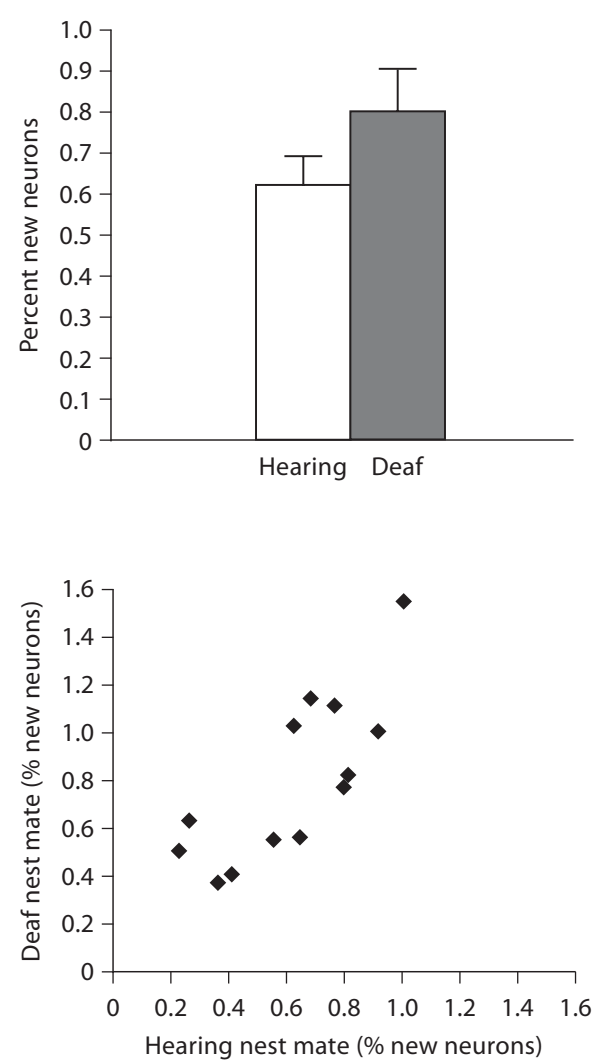

Fig. 3. One member in each of 13 nest mate pairs was deafened in adulthood by bilateral cochlea removal, injected with $\left[{ }^{3} \mathrm{H}\right]$-thymidine two weeks later, and killed one month after the last $\left[{ }^{3} \mathrm{H}\right]$-thymidine injection. Deafening had a significant effect on neuron addition (upper fig.; $\mathrm{p}=0.009$ ). However, a strong similarity between nest mate pairs persisted (lower fig.; $p=0.03$ ). Each diamond in the lower figure represents the percentage of all HVC neurons labeled with $\left[{ }^{3} \mathrm{H}\right]$-thymidine for a nest mate pair, with values for deafened birds plotted on the $y$-axis and values for hearing birds plotted on the $\mathrm{x}$-axis.

We also explored the potential contributions to nest mate similarities of variation in adult social housing during the experiment. Although all cages housed 3-4 birds and, in all but one case, cages housed birds from at least two nests it is possible that being housed entirely within the same cage might account for co-variation within families. To explore this possibility, we divided subjects into two groups; cases where nest mate groups were in the same cage versus cases where at least one nest mate was housed separately. Figure 2 (lower panel) shows individual values for birds as they relate to the two housing cat- egories. There were 6 families and a total of 14 birds in the former group (all nest mates housed together) and 14 families with a total of 32 birds in the latter group (nest mate groups distributed across 2 or more cages). A twoway ANOVA using nest of origin and housing condition as the independent variables yielded a significant main effect for nest of origin $\left(\mathrm{F}_{(13,31)}=2.52 ; \mathrm{p}=0.017\right)$ but not housing condition $\left(\mathrm{F}_{(1,31)}=0.19 ; \mathrm{p}=0.66\right)$. Additional analyses, restricted to families whose members were distributed across cages indicate that despite being separately housed as adults, birds who had shared the same nest had similar rates of neuron addition $\left(\mathrm{F}_{(13,18)}=2.54 ; \mathrm{p}=\right.$ $0.034)$. This is particularly evident in nest mate groups 7 and 13. In both cases, all three birds that had been nest mates were housed in different cages yet had very similar densities of new neurons. Moreover, in nest mate groups 3 and 11, also containing three birds each, nearest neighbors in terms of new neuron densities were nest mates that had been housed separately as adults.

Figure 3 summarizes rates of HVC neuron addition after one member in each of 13 nest mate pairs was deafened prior to injections of $\left[{ }^{3} \mathrm{H}\right]$-thymidine. When compared to their hearing nest mates, deafened birds had significantly higher proportions of new HVC neurons (fig. 3 , upper panel. Matched samples t test, $\mathrm{t}_{(12)}=3.1, \mathrm{p}=0.004$ ). However, despite the fact that deafening altered neuron addition rates, there was still a significant correlation between nest of origin and neuron addition (fig. 3, lower panel. $\left.\mathrm{F}_{(12,13)}=2.91, \mathrm{p}=0.033 ; \mathrm{R}^{2}=0.49\right)$.

\section{Discussion}

We believe this is the first demonstration that natural variation in neuron incorporation correlates with family membership. One potential explanation for this result is that nest mates co-varied due to being housed together as adults; however, results from analyses restricted to families where members were distributed across cages as adults suggest that a common adult social environment cannot explain our findings. We also tested whether or not altered auditory experience in adulthood would disrupt nest mate concordance on HVC neuron addition. Deafened birds had significantly higher rates of neuron addition than their hearing nest mates. This trend was in the opposite direction compared to previous work [Wang et al., 1999]. More recent work indicates that the effect of deafening is dependent on social context and requires equal representation of ages and nest mates across experimental groups. A more detailed treatment of these 
issues is forthcoming [Hurley et al., in preparation, also see Wilbrecht and Kirn, 2004]. Regardless, despite the fact that deafening clearly altered neuron addition, there was still a significant correlation between nest of origin and neuron addition. Thus, similarities between nest mates are robust and underlying mechanisms constrain changes in neuron addition that accompany changes in adult auditory experience. The results suggest that factors associated with parentage, operating before hatching or in the early post-hatch environment might have longlasting, perhaps permanent, influences on neuron addition.

In contrast to previous work, we failed to find a significant relationship among nest mates with respect to HVC volume [Airey et al., 2000; Williams et al., 2003] or neuron number [Ward et al., 2001]. This is probably the result of a relatively small sample size for birds of known parentage and much smaller overall variation in these attributes in our birds compared to other reports. For example, in the present work the range of $\mathrm{HVC}$ volumes and total neuron numbers varied by less than 2 -fold (data not shown) compared to the 4 -fold variation in other reports [Ward et al., 2001], including our previous work [Wang et al., 2002] that used the same estimation methods employed in the present study. Perhaps neuron incorporation rates show even stronger co-variation among nest mates than either HVC volume or total neuron number.

\section{Relative Contributions of Genotype and Environment}

It will be interesting to identify the relative contributions of genotype and environment to similarities among zebra finch nest mates. Work in mice suggests that variation in genotype can impact adult neurogenesis. For example, inbred mouse strains differ in rates of hippocampal neurogenesis [Kempermann et al., 1997, 2006]. In songbirds, several indirect lines of evidence suggest that rates of adult HVC neuron incorporation are heritable. HVC volume and neuron number co-vary among siblings and are remarkably resilient in the face of many forms of environmental manipulation, including the ability to hear and opportunities to learn song during development [DeVoogd, 2004]. Singing rate (number of songs per unit time) is known to influence HVC neuron incorporation [Li et al., 2000; Alvarez-Borda and Nottebohm, 2002]. Interestingly, singing rates in zebra finches show high concordance between fathers and sons and between brothers, even when day-old hatchlings are raised by foster parents [Houtman, 1992]. Moreover, concordance for singing rates between brothers is resistant to early post-hatching nutritional stress [Birkhead et al.,
1999], despite the fact that dietary restriction affects HVC development and song quality [Buchanan et al., 2004; Nowicki and Searcy, 2004; but see Gil et al., 2006]. Thus, variation in genotype could influence adult neuron incorporation rates, perhaps due to a linkage between singing and adult neurogenesis.

If neuron incorporation rates are heritable, it is likely that we have underestimated co-variation among siblings. Many of the birds used in this study were hatched in a large aviary with several breeding pairs and nest boxes, so there is the possibility that unrelated or partial siblings shared the same nest. It is also possible that genetically related birds were hatched in different nests. Although we have detailed breeding records of birds in our colony, we replace some breeding stock every $1-2$ years and suppliers do not typically provide records of parentage. For these reasons, 'nest of origin' might not always be an accurate indicator of distinct sibling groups.

There is also indirect support for the suggestion that nest mate similarities in adult neuron incorporation result from shared early experience. In rats, early experience with stressors is known to impact adult hippocampal neurogenesis [Mirescu et al., 2004]. In zebra finches, maternal environment, and more specifically the in ovo environment, has been shown to correlate with adult singing rates in sons [Forstmeier et al., 2004]. Moreover, egg testosterone $(\mathrm{T})$ levels are good predictors of other HVC attributes, and intra-clutch egg $T$ levels vary less than T levels across clutches of eggs [Ward et al., 2001].

Collectively, these results raise the possibility that both genotype and early environment contribute to the observed co-variation in HVC neuron addition among nest mates. Intriguingly, regardless of the relative contributions of environment and genotype to adult neuron replacement, female mate choice might play a pivotal role in this process. Females possibly select mates that confer male genes for singing and neuron addition to sons. Alternatively, or in addition, females could select mates that induce a particular egg environment that biases their sons' singing rates and adult neuron addition. For example, female zebra finches deposit more $\mathrm{T}$ in eggs following mating with 'sexy' males [Gil et al., 1999]. Once the mechanism(s) for nest mate similarities is elucidated, this might provide a powerful new tool for manipulating neuron addition in the search for functional consequences of this extreme form of plasticity.

\section{Locus of Constraints on Adult Neurogenesis}

We also showed that the contributions of nest of origin to adult neuron addition rates are long lasting, as adult 
deafening did not abolish nest mate similarities. This could be because early developmental events limit the extent to which adult rates of neuron incorporation respond to changing behavioral context. There is direct evidence that adult-formed HVC neurons respond to sound [Paton and Nottebohm, 1984]. Most adult-formed HVC neurons project to the robust nucleus of the arcopallium (HVCRA) and HVC-RA neurons more generally exhibit highly selective responses to playbacks of the bird's own song [Alvarez-Buylla et al., 1990; Mooney and Prather, 2005]. Thus, nest mate similarities in neuron addition persisted even when at least one type of experience known to influence new neuron activity and that is also profoundly important for song learning and maintenance [Nordeen and Nordeen, 1992; Lombardino and Nottebohm, 2000] was dramatically altered. However, it is also possible that deafening did not alter the most important behavioral variable. The relationship between amount of singing and neuron addition might be due to song-related motor rather than auditory activity. We did not record song rates in the birds used in this study and it is possible that potential nest mate similarities in singing rate were not disrupted when one member of a pair was deafened. As summarized earlier, there is strong evidence for sibling concordance on singing rate as well as a remarkable resilience of singing rate in a number of contexts. Perhaps it is the amount of singing (and associated pre-motor activity) that is constrained by early developmental events and that behavioral concordance among nest mates drives similarities in rates of HVC neuron addition.

\section{Functional Implications of Nest Mate Similarities}

The functions of adult HVC neurogenesis remain unclear and so we do not know if and how variability in neuron incorporation might influence behavior. However, singing may regulate the initial addition of new neurons and their survival might be determined by the extent to which they allow birds to achieve and maintain a target song acoustic structure [Wilbrecht and Kirn, 2004]. It is worth noting that in a previous report there was a strong tendency for sibling relationships to predict absolute changes in spectral and temporal features of song after adult deafening [Brainard and Doupe, 2000, see fig. 4]. Moreover, rate of song deterioration after deafening is positively correlated with rates of neuron addition, perhaps due to corruption of song motor programs by ongoing HVC neuron addition in the absence of song auditory feedback [Scott et al., 2000]. If true, this would suggest that co-variation in neuronal incorporation rates among nest mates permits (and constrains) behavioral plasticity.
Adult neurogenesis and neuronal replacement across mammalian and avian systems have been viewed as mechanisms for preserving almost unlimited flexibility in the postnatal brain; however, there is increasing evidence that this flexibility has rules. It has been known for many years that new neurons are added to some but not all brain regions. Recent work indicates that neurons formed in specific regions of the ventricular zone (VZ) adopt specific locations and phenotypes in adult birds [Stellitano et al., 2003; Scott and Lois, 2007] and mammals [Young et al., 2007]. When portions of the VZ are transplanted to new locations in adult mammals, progeny do not alter their phenotype, suggesting that cell fate is determined in the VZ, and specific stem cells produce a narrow range of neuron types [Merkle et al., 2007]. Attempts to induce neuron incorporation in novel regions have had mixed results [Magavi et al., 2000; Scharff et al., 2000; Cheng et al., 2004]. Here we add an additional constraint in that rates of adult neuron incorporation are regulated, in part, by the long lasting effects of experiential or genetic factors operating during development. Although these findings pose new challenges with respect to understanding the functions of neuronal replacement and the therapeutic use of stem cells, the more we learn about these rules, the closer we may come to achieving both of these goals.

\section{Acknowledgments}

This work was supported by PHS Grants \# NS29843, DC004724 and the Scott Family Charitable Trust. We thank Michael Singer, David Airey, and Dick Darlngton for statistical advice.

References Airey DC, Castillo-Juarez H, Casella G, Pollak EJ, DeVoogd TJ (2000) Variation in the volume of zebra finch song control nuclei is heritable: developmental and evolutionary implications. Proc Biol Sci 267:2099-2104.

-Alvarez-Borda B, Nottebohm F (2002) Gonads and singing play separate, additive roles in new neuron recruitment in adult canary brain. J Neurosci 22:8684-8690.

-Alvarez-Buylla A, Kirn JR, Nottebohm F (1990) Birth of projection neurons in adult avian brain may be related to perceptual or motor learning. Science 249:1444-1446.

- Barami K, Iversen K, Furneaux H, Goldman SA (1995) Hu protein as an early marker of neuronal phenotypic differentiation by subependymal zone cells of the adult songbird forebrain. J Neurobiol 28:82-101. 
Birkhead TR, Fletcher F, Pellatt EJ (1999) Nestling diet, secondary sexual traits and fitness in the zebra finch. Proc R Soc Lond B: Biol Sci 266:385.

- Brainard MS, Doupe AJ (2000) Interruption of a basal ganglia-forebrain circuit prevents plasticity of learned vocalizations. Nature 404: 762-766.

Brenowitz EA (1991) Altered perception of species-specific song by female birds after lesions of a forebrain nucleus. Science 251: 303-305.

Buchanan KL, Leitner S, Spencer KA, Goldsmith AR, Catchpole CK (2004) Developmental stress selectively affects the song control nucleus HVC in the zebra finch. Proc Biol Sci 271:2381-2386.

Cheng MF, Peng JP, Chen G, Gardner JP, Bonder EM (2004) Functional restoration of acoustic units and adult-generated neurons after hypothalamic lesion. J Neurobiol 60:197-213.

Clayton DF, Alvarez-Buylla A (1989) In situ hybridization using PEG-embedded tissue and riboprobes: Increased cellular detail coupled with high sensitivity. J Histol Cytol 37:389393.

- Coggeshall RE, Lekan HA (1996) Methods for determining numbers of cells and synapses: a case for more uniform standards of review. J Comp Neurol 364:6-15.

Darlington RB, Smulders TV (2001) Problems with residual analysis. Anim Behav 62:599602 .

-DeVoogd TJ (2004) Neural constraints on the complexity of avian song. Brain Behav Evol 63:221-232.

Eales LA (1985) Song learning in Zebra Finches: Some effects of song model availability on what is learnt and when. Anim Behav 33: 1293-1300.

- Forstmeier W, Coltman DW, Birkhead TR (2004) Maternal effects influence the sexual behavior of sons and daughters in the zebra finch. Evolution 58:2574-2583.

-Gentner TQ, Hulse SH, Bentley GE, Ball GF (2000) Individual vocal recognition and the effect of partial lesions to HVc on discrimination, learning, and categorization of conspecific song in adult songbirds. J Neurobiol 42:117-133.

Gil D, Graves J, Hazon N, Wells A (1999) Male attractiveness and differential testosterone investment in zebra finch eggs. Science 286 : 126-128.

-Gil D, Naguib M, Riebel K, Rutstein A, Gahr M (2006) Early condition, song learning, and the volume of song brain nuclei in the zebra finch (Taeniopygia guttata). J Neurobiol 66: 1602-1612.

-Houtman AM (1992) Female zebra finches choose extra-pair copulations with genetically attractive males. Proc R Soc Lond 249: $3-6$.
Kempermann G, Kuhn HG, Gage FH (1997) Genetic influence on neurogenesis in the dentate gyrus of adult mice. Proc Natl Acad Sci USA 94:10409-10414.

Kempermann G, Chesler EJ, Lu L, Williams RW, Gage FH (2006) Natural variation and genetic covariance in adult hippocampal neurogenesis. Proc Natl Acad Sci USA 103:780785.

Konigsmark B (1970) Methods for counting neurons. In: Research Methods in Neuroanatomy (Nauta WJH, Ebbesson S, eds), pp 315340. New York: Springer.

Leuner B, Gould E, Shors TJ (2006) Is there a link between adult neurogenesis and learning? Hippocampus 16:216-224.

Li XC, Jarvis ED, Alvarez-Borda B, Lim DA, Nottebohm F (2000) A relationship between behavior, neurotrophin expression, and new neuron survival. Proc Natl Acad Sci USA 97: 8584-8589.

Lipkind D, Nottebohm F, Rado R, Barnea A (2002) Social change affects the survival of new neurons in the forebrain of adult songbirds. Behav Brain Res 133:31-43.

Lombardino AJ, Nottebohm F (2000) Age at deafening affects the stability of learned song in adult male zebra finches. J Neurosci 20:5054-5064.

Magavi SS, Leavitt BR, Macklis JD (2000) Induction of neurogenesis in the neocortex of adult mice. Nature 405:951-955.

Merkle FT, Mirzadeh Z, Alvarez-Buylla A (2007) Mosaic organization of neural stem cells in the adult brain. Science 317:381-384.

- Mirescu C, Peters JD, Gould E (2004) Early life experience alters response of adult neurogenesis to stress. Nat Neurosci 7:841-846.

Mooney R, Prather JF (2005) The HVC microcircuit: the synaptic basis for interactions between song motor and vocal plasticity pathways. J Neurosci 25:1952-1964.

Morrison RG, Nottebohm F (1993) Role of a telencephalic nucleus in the delayed song learning of socially isolated zebra finches. J Neurobiol 24:1045-1064.

Nordeen KW, Nordeen EJ (1992) Auditory feedback is necessary for the maintenance of stereotyped song in adult zebra finches. Behav Neural Biol 57:58-66.

Nottebohm F, Stokes TM, Leonard CM (1976) Central control of song in the canary, Serinus canarius. J Comp Neurol 165:457-486.

-Nottebohm F, Alvarez-Buylla A, Cynx J, Kirn J, Ling C-Y, Nottebohm ME, Suter R, Tolles A, Williams H (1990) Song learning in birds: the relation between perception and production. Phil Trans R Soc Lond B 329:115-124.

Nowicki S, Searcy WA (2004) Song function and the evolution of female preferences: why birds sing, why brains matter. Ann NY Acad Sci 1016:704-723.

Paton JA, Nottebohm F (1984) Neurons generated in the adult brain are recruited into functional circuits. Science 225:1046-1048.
-Scharff C, Kirn JR, Grossman M, Macklis JD, Nottebohm F (2000) Targeted neuronal death affects neuronal replacement and vocal behavior in adult songbirds. Neuron 25: 481-492.

Scott BB, Lois C (2007) Developmental origin and identity of song system neurons born during vocal learning in songbirds. J Comp Neurol 502:202-214.

Scott LL, Nordeen EJ, Nordeen KW (2000) The relationship between rates of $\mathrm{HVc}$ neuron addition and vocal plasticity in adult songbirds. J Neurobiol 43:79-88.

Smithson K, MacVicar B, Hatton G (1983) Polyethylene Glycol embedding: A technique compatible with immunocytochemistry, enzyme histochemistry, histofluorescence and intracellular staining. J Neurosci Meth 7:2741.

Sokal RR, Rohlf FJ (1981) Biometry, 2nd ed. New York: WH Freeman Co.

Stellitano KE, Zollinger S, Kirn JR (2003) A retroviral analysis of neurons formed in the adult zebra finch brain. In: Soc Neurosci Abst. Washington DC.

-Wang N, Aviram R, Kirn JR (1999) Deafening alters neuron turnover within the telencephalic motor pathway for song control in adult zebra finches. J Neurosci 19:1055410561.

Wang N, Hurley P, Pytte C, Kirn JR (2002) Vocal control neuron incorporation decreases with age in the adult zebra finch. J Neurosci 22: 10864-10870.

Ward BC, Nordeen EJ, Nordeen KW (2001) Anatomical and ontogenetic factors producing variation in $\mathrm{HVc}$ neuron number in zebra finches. Brain Res 904:318-326.

Wilbrecht L, Kirn JR (2004) Neuron addition and loss in the song system: Regulation and function. Ann NY Acad Sci 1016:659-683.

Wilbrecht L, Williams H, Gangadhar N, Nottebohm F (2006) High levels of new neuron addition persist when the sensitive period for song learning is experimentally prolonged. J Neurosci 26:9135-9141.

Williams H, Connor DM, Hill JW (2003) Testosterone decreases the potential for song plasticity in adult male zebra finches. Horm Behav 44:402-412.

-Young KM, Fogarty M, Kessaris N, Richardson WD (2007) Subventricular zone stem cells are heterogeneous with respect to their embryonic origins and neurogenic fates in the adult olfactory bulb. J Neurosci 27:82868296

Zar J (1984) Biostatistical Analysis, 2nd ed. Englewood Cliffs, NJ: Prentice Hall. 